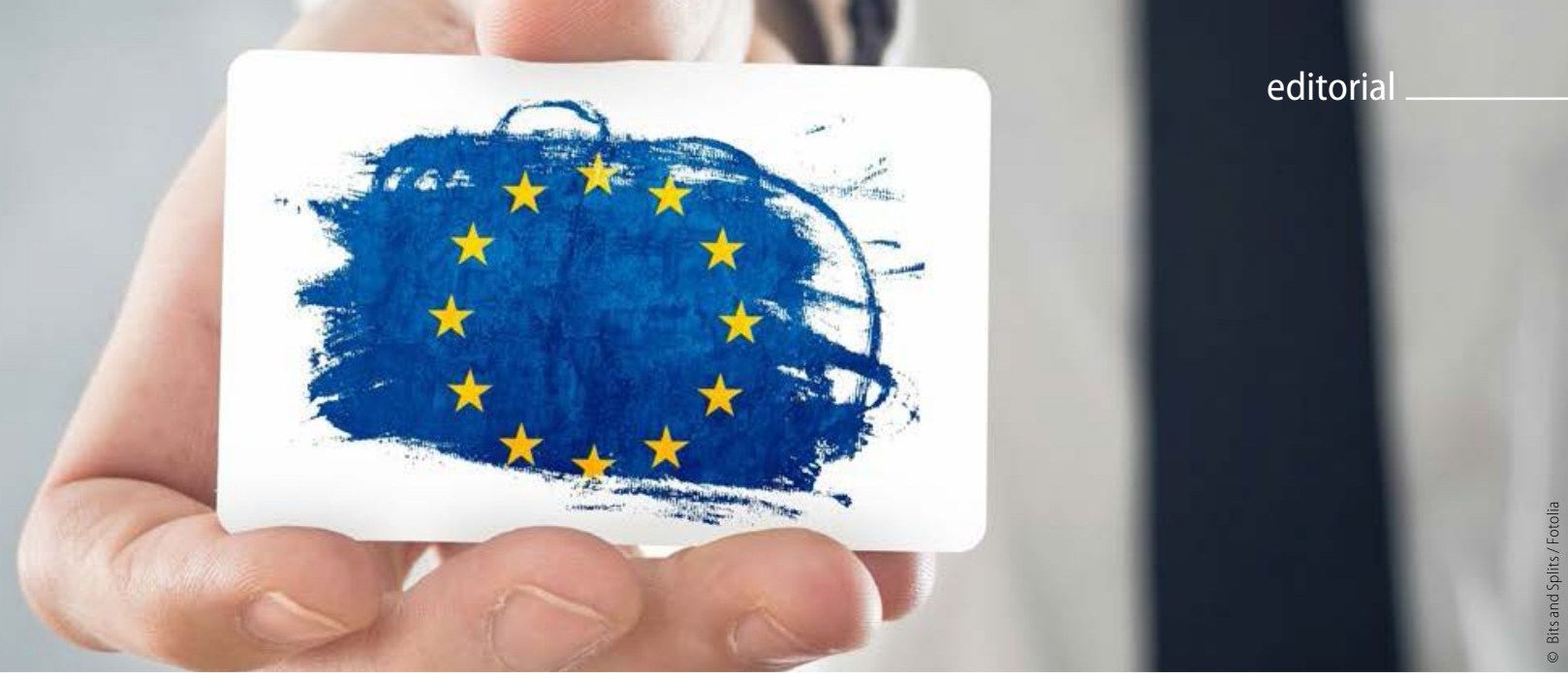

\title{
Europa gestalten
}

Liebe Kolleginnen, liebe Kollegen,

friedlich, geeint und wirtschaftlich erfolgreich - so haben sich die Gründer der EU visionär das Zusammenleben vorgestellt. Gegenwärtig scheint allerdings nicht nur das Wetter in Europa verrückt zu spielen, sondern auch die politische Landschaft ist von manch heftigem Gewitter betroffen. Riesige Herausforderungen sind zu bewältigen: die Flüchtlingskrise, das Aufblühen rechtspopulistischer Bewegungen und der per Referendum abgestimmte Brexit. Der Zusammenhalt Europas wird auf die Probe gestellt. Dabei darf in einem bürgernahen Europa die Maxime keineswegs heißen, durch basisdemokratische Entscheidungen die Errungenschaften der europäischen Integration und Integrität zu untergraben oder gar zu zerstören. Im Gegenteil, es muss intensive Diskussionen und ein Zusammendenken geben, um die politischen Konflikte zu lösen und die europäischen Werte zu verteidigen: die Achtung der Würde des Menschen, Freiheit, Gleichheit, Solidarität, Demokratie, die Wahrung der Menschenrechte, und dies auf Basis der Rechtsstaatlichkeit.

Subsidiarität in Europa bedeutet, dass die EU nur das regeln sollte, was Mitgliedstaat, Land, Stadt oder Kommune selbst nicht besser regeln kann. Ein gemeinsames Handeln auf europäischer Ebene kann jedoch nur dann gelingen, wenn das Gebot der Bürgernähe berücksichtigt wird und die EU sich daran prinzipiell ausrichtet.

\section{Mehr als nur Wirtschaftsmotor}

Die Europäische Kommission priorisiert aktuell auf ihrer Agenda Wachstum und Förderung von Beschäftigung durch eine Vertiefung des Binnenmarkts. Bereits 2010 wurden etwa 3,7 Millionen Unternehmen im freiberuflichen Dienstleistungssektor mit rund elf Millionen arbeitenden Menschen klassifiziert. Es wurde ein Mehrwert von mehr als einer halben Billion Euro generiert. In Deutschland bilden die freien Berufe mit knapp 1,3 Millionen Selbstständigen und deren 3,4 Millionen Mitarbeitern einen starken Motor der Beschäftigung und des Wachstums. Sie erwirtschaften im Jahr 381 Milliarden Euro, was rund zehn Prozent des Bruttoinlandsprodukts entspricht. Die Bedeutung des Freien Berufs geht jedoch weit über die rein ökonomische Betrachtungsweise hinaus, was gerade im Gesundheitssektor deutlich wird. Wesentliche Merkmale der Freiberuflichkeit sind: die Gemeinwohlbindung und die selbstständige und persönliche Erbringung einer Dienstleistung, fachlich und wirt-

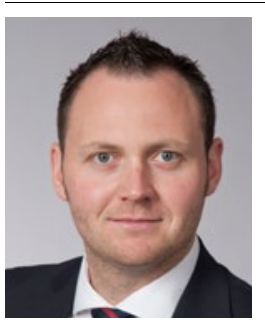

\section{Dr. Thomas Wolf}

Mitglied des FVDZ Bundesvorstandes

schaftlich unabhängig. Essenziell ist dabei das besondere Vertrauensverhältnis zwischen Auftraggeber und -nehmer und die Zurückstellung des Interesses maximaler Gewinnerzielung.

\section{Nivellierung nach unten verhindern}

Die drohende Deregulierung der Freien Berufe mit einhergehendem Abbau von Berufsreglementierungen darf weder die Zuständigkeit der Mitgliedstaaten in Frage stellen noch zu Lasten von Gemeinwohlinteressen ausgelegt werden. Qualitätsund Sicherheitsstandards sind höchstes Gut, hohe Ausbildungsstandards müssen daher im sensiblen medizinischen Bereich erhalten bleiben. Eine Nivellierung nach unten muss unbedingt verhindert werden.

Durch den Erhalt der freiberuflichen Merkmale kann sowohl die gesellschaftliche als auch wirtschaftliche Entwicklung in vielen europäischen Staaten nachhaltig und zukunftsfähig positiv beeinflusst werden. Wir müssen lernen, unsere standespolitischen Handlungsoptionen besser aufeinander abzustimmen. Wichtig zur Erfüllung der Ziele ist dabei unausweichlich das Bilden von Allianzen, sowohl auf deutscher als auch auf international europäischer Ebene. Es gilt, statt sich gegenseitig zu bekämpfen, Mehrwerte zu erkennen, offen zu diskutieren und Lösungsansätze zu entwickeln. Europa lebt von offenen Debatten. Nutzen wir die Möglichkeiten, schaffen wir Perspektiven und gestalten wir Europa mit.

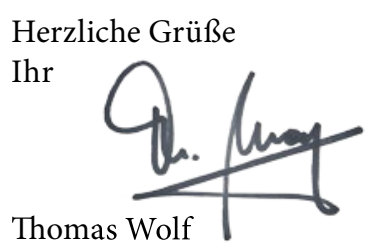

